\title{
ENTRE A FARDA E A SOCIEDADE DE RISCO: O CORPO DE BOMBEIROS MILITAR COMO INSTRUMENTO DE MANUTENÇÃO DA ORDEM URBANA E HABITACIONAL
}

\author{
Pedro Henrique Moreira da Silva ${ }^{1}$ \\ Valdênia Geralda de Carvalho ${ }^{2}$
}

\section{RESUMO}

O estudo pretende suscitar as questões relacionadas à sociedade de risco, no que tange às percepções contemporâneas a respeito das novas atividades e posturas sociais, sob o olhar de Ulrich Beck. Recorrendo ao método hipotéticodedutivo e à dialética, buscar-se-á demonstrar, a partir das considerações iniciais, o papel do Corpo de Bombeiros Militar na manutenção da ordem habitacional e urbanística. Isto é, serão analisadas as condutas da instituição à luz dos princípios da precaução e prevenção - indispensáveis para os "cenários de risco" que se consolidam com o paradigma da modernidade. Considerar-se-á, portanto, as tarefas relacionadas à Defesa Civil, bem como a prevenção e combate a incêndio e pânico, cujo fim é assegurar o bem-estar urbano e social. Nesse sentido, justifica-se a pesquisa pela indispensabilidade do Corpo de Bombeiros Militar na garantia de modos dignos de organização habitacional e urbana que refletem, direta e indiretamente, no mandamento constitucional que assegura às gerações um meio ambiente equilibrado.

Palavras-chave: Sociedade de risco. Corpo de Bombeiros Militar. Habitação e Urbanismo. Defesa Civil. Combate e prevenção a incêndio e pânico.

\footnotetext{
${ }^{1}$ Mestrando em Direito Ambiental e Desenvolvimento Sustentável pela Escola Superior Dom Helder Câmara (ESDHC).Advogado. Bacharel em Direito pela Escola Superior Dom Helder Câmara (ESDHC). Bacharelando em Letras pela Universidade Federal de Minas Gerais (UFMG).E-mail: pedroadvdireito@gmail.com.

2 Orientadora. Doutora e Mestre em Teoria do Estado e Direito Constitucional pela Pontifícia Universidade Católica do Rio de Janeiro (PUC-Minas). Especialista em Ciências Penais pela Escola Superior do Ministério Público. Especialista em Direitos Humanos pela Fundação Movimento Direito e cidadania e FAJE. Professora.
} 


\title{
BETWEEN THE MILITARY UNIFORM AND THE RISK SOCIETY: THE MILITARY FIRE BRIGADE AS AN INSTRUMENT FOR THE MAINTENANCE OF THE URBAN AND HOUSING ORDER
}

\begin{abstract}
The study intends to raise the questions related to the society of risk, with regard to the contemporary perceptions regarding the new activities and social postures, under the eyes of Ulrich Beck. Using the hypothetical-deductive method and the dialectic, we will try to demonstrate, starting from the initial considerations, the role of the Military Fire Brigade in the maintenance of housing and urban planning. That is, the conduct of the institution will be analyzed in the light of the principles of precaution and prevention indispensable for the "risk scenarios" that consolidate with the paradigm of modernity. Civil defense tasks will be considered, as will the prevention and combat of fire and panic, with the aim of ensuring urban and social well-being. In this sense, the search for the indispensability of the Military Fire Brigade is justified in guaranteeing decent housing and urban organization ways that reflect, directly and indirectly, the constitutional mandate that guarantees generations a balanced environment.
\end{abstract}

Keywords: Society of risk. Military Fire Brigade. Housing and Urbanism. Civil Defense. Combat and fire prevention and panic.

\section{RESUMEN}

El estudio pretende suscitar las cuestiones relacionadas con la sociedad de riesgo, en lo que se refiere a las percepciones contemporáneas acerca de las nuevas actividades y posturas sociales, bajo la mirada de Ulrich Beck. Recurriendo al método hipotéticodeductivo ya la dialéctica, se buscará demostrar, a partir de las consideraciones iniciales, el papel del Cuerpo de Bomberos Militar en el mantenimiento del orden habitacional y urbanístico. Es decir, se analizar las conductas de la institución a la luz de los principios de precaución y prevención, indispensables para los "escenarios de riesgo" que se consolidan con el paradigma de la modernidad. Se considerará, por lo tanto, las tareas relacionadas con la Defensa Civil, así como la prevención y lucha contra incendios y pánico, cuyo fin es asegurar el bienestar urbano y social. En ese sentido, se justifica la investigación por la indispensable del Cuerpo de Bomberos Militar en la garantía de modos dignos de organización habitacional y urbana que reflejan, directa e indirectamente, en el mandamiento constitucional que asegura a las generaciones un medio ambiente equilibrado.

Palabrasclave: Sociedade de riesgo. Cuerpo de Bomberos Militar. Vivienda y Urbanismo. Defensa Civil. Combate y prevención de incêndios y pánico.

\section{Artigo Recebido em 28/03/2019 e Aceito em 08/08/2019}




\section{INTRODUÇÃO}

A verificação das demandas de produção-consumo ${ }^{3}$, de crescimento econômico e de desenvolvimento das cidades permite a conclusão de que se instituiu uma sociedade de risco na modernidade. Isto é, as relações entre os indivíduos e entre indivíduos e tecnologias e estruturas é de constante incerteza - o que coloca em dúvida a estabilidade da ordem urbanística e habitacional, principalmente.

Nesse sentido, a pesquisa se propõe - por meio do método hipotéticodedutivo e dialético - traçar breves considerações acerca do paradigma da "sociedade de risco" ${ }^{4}$ e apresentar o Corpo de Bombeiros Militar (CBM) como um dos instrumentos públicos para modulação, manutenção e garantia da ordem urbanística e habitacional. Isso porque, conforme se verifica, as formações e delegações legais fazem do CBM uma instituição capacitada para a análise de riscos e formulação de condutas estratégicas e táticas para prevenção e combate do caos.

Para tanto, serão tecidas as devidas explanações acerca da tarefa palpável do CBM, na medida em que lhes incumbem os deveres relacionados à Defesa Civil e à prevenção de incêndio e pânico - o que é indispensável para a estabilidade e bem-estar nas cidades, sobretudo se considerar-se que essas atividades são [e devem ser] sustentadas pelos princípios da prevenção e da precaução. Assim, pela pertinência do debate, justifica-se a pesquisa pela importância da demonstração do papel do Corpo de Bombeiros Militar na sociedade, como instrumento de manutenção da ordem urbanística e habitacional.

\footnotetext{
3 Base da dinâmica do sistema capitalista, que orienta a utilização dos bens naturais para produção de riquezas e posterior inserção no mercado.

4 Teoria criada por Beck (2012) que afirma que o desenvolvimento das tecnologias gera riscos constantes em razão das incertezas científicas que acompanham os avanços tecnológicos.
} 


\section{BREVES CONSIDERAÇÕES ACERCA DA SOCIEDADE DE RISCO}

O paradigma da modernidade, aliado aos modelos de consumo e produção, levaram a uma série de tragédias e entraves que, até os anos 80 , eram vistas como "acidentes" decorrentes [e necessários] ao progresso econômico e crescimento dos centros urbanos. Não obstante, parece incontroverso que o agravamento dos problemas ambientais, estruturais e de segurança são relacionados aos processos de desenvolvimento do conhecimento - que não se preocupam em promover o controle dos efeitos de novos padrões tecnológicos, por exemplo. (BECK, 2011, p. 113)

Assim, diz-se que os indivíduos do século XXI vivem em um mundo fora do controle, pautado nas incertezas em razão da não mobilização para avaliação e análises dos riscos que os comportamentos sociais acarretam. Trata-se de

um mundo governado inteiramente pelas leis da probabilidade, onde tudo é mensurável e calculável. Esta palavra também é comumente usada para referir-se a incertezas não quantificáveis, a riscos que não podem ser mensurados (...) são incertezas fabricadas. (BECK, 2006, p. 5)

As pessoas e o meio ambiente são submetidos aos efeitos do progresso e, por consequência, a riscos mais significativos. Muitas das vezes, esses riscos são superiores às capacidades de mitigação e proteção, de forma que se constitui um novo ser no espaço, o homo predator. (KALOF, FITZGERALD, 2003, p. 98)

$\mathrm{Na}$ sociedade de risco, o indivíduo, percebendo as incertezas que o cercam, tende a promover reflexões baseadas nos prós e contras das interações "Homem-tecnologias", de forma que a formação de uma consciência

5 Na perspectiva sociológica, trata-se da evolução do Homo Sapiens. Isto é, um homem que desenvolve-se no meio através de posturas e condutas predatórias e exploratórias. 
possibilita o surgimento de métodos e mecanismos para aplacar os resultados da incerteza. (FIGUEIREDO, 2018, p. 305)

Assim,

\begin{abstract}
A avaliação do risco é estimar o risco e a gestão do risco significa a mitigação ou controle para um nível "aceitável". Tal postura apresenta não apenas a esperança de domar a incerteza, mas também de assegurar a ação política através do conhecimento científico. Assim surgiu o conceito de análise do risco. Rowe (1989) define seu conceito da análise de risco, como uma ferramenta de análise política que utiliza uma base composta do conhecimento científico e da ciência da informação política para subsidiar a tomada de decisões. (FIGUEIREDO, 2018, p. 305)
\end{abstract}

Diz-se, portanto, que a análise de risco é o caminho para a teoria da decisão, que importa nos resultados relacionados à proteção social. Impera a constante avaliação das condicionantes dos comportamentos [novos e antigos] e a construção de planos estratégicos e táticos para garantia de uma ordem que - conforme as incertezas contemporâneas - não é estrutura permanente.

Nas cidades, para além das questões tecnológicas, é possível verificar que os modelos de edificações e a disposição de espaços leva a igual incerteza, na medida em que ocupações se apartam mais das lógicas de segurança básica. O planejamento e utilização de mecanismos de controle do bem-estar são elencados ao status burocrático, na utopia de uma ordem estática.

Nesse sentido, incumbe aos órgãos e instrumentos estatais uma dinâmica contra-hegemônica para alcance e superação dos riscos e incertezas da sociedade. Ora, se as fragilidades culturais e de perspectiva comunitária são afetadas por demandas de produção-consumo e desenvolvimento, impera às especializadas posturas de garantia e imposição da ordem - sob risco de violação de direitos conquistados ao longo de dimensões diversas ${ }^{6}$, desde a Revolução Francesa.

6 Dimensões liberais (Locke), sociais (Marx) ou coletivas. 
Assim, traz-se para a discussão o papel do Corpo de Bombeiros Militar que, pela formação e construção como entidade qualificada, pode atuar na mitigação e proteção de riscos. Esse papel assume importância ainda mais notável no caso de medidas para promoção de cidades ordenadas e resilientes $^{7}$, que sejam capazes de resistir a fragilidades estruturais e a incêndios e pânico - principalmente. Isso porque, considerando-se os volumes populacionais, a desordem ocasionada por desastres pode representar 0 colapso dos moldes da sociedade, com a desestruturação de paradigmas que sustentam a contemporaneidade.

\section{O CORPO DE BOMBEIROS MILITAR COMO INSTRUMENTO PARA ORDEM URBANÍSTICA E HABITACIONAL}

O Corpo de Bombeiros Militar integra o Sistema Único de Segurança Pública (SUSP - Lei n. 13.675, de 11 de junho de 2018), integrado por militares estaduais que atuam como força auxiliar e reserva do Exército Brasileiro. Notese, entretanto, que a vinculação a que se refere não influencia na autonomia da instituição que, conforme se verifica, segue sendo uma das de maior prestígio no país. (MARTINS, 2001)

Desde a Carta Magna de 1988, o Corpo de Bombeirosrecebeu a atribuição constitucional inscrita no artigo 144, §§ $5^{\circ}$ e $6^{\circ}$, que delega à instituição o dever de zelar pela segurança pública e pela Defesa Civil, além das competências previstas em lei ordinária estadual, in verbis:

Artigo 144.

§ 5ํàs polícias militares cabem a polícia ostensiva e a preservação da ordem pública; aos corpos de bombeiros militares, além das atribuições definidas em lei, incumbe a execução de atividades de defesa civil.

$\S 6^{\circ}$ As polícias militares e corpos de bombeiros militares, forças auxiliares e reserva do Exército, subordinam-se, juntamente com as polícias civis, aos Governadores dos Estados, do Distrito Federal e dos Territórios. (BRASIL, 1988)

$7 \quad$ Cidades capazes de responder aos riscos e desastres. 
No que tange à organização da Defesa Civil, tem gênese marcada pelo Sistema Nacional de Defesa Civil (SINDEC), de 1988, posteriormente atualizado pela Lei Federal 12.608, de 2012. Referida legislação instituiu a Política Nacional de Proteção e Defesa Civil - parte do Sistema Nacional de Proteção e Defesa Civil, ligada ao Conselho Nacional de Proteção e Defesa Civil, o CONPDEC. A partir da estruturação no Princípio da Legalidade ${ }^{8}$, ficam as atividades de Defesa Civil ligadas a manobras e planejamentos de "prevenção, mitigação, preparação para emergência e desastres e recuperação de cenários atingidos por desastres." (CBMGO, 2018, p. 16)

Ademais, sabe-se que outras competências legais dizem respeito ao salvamento, socorro, resgate e extinção de incêndios, além dos demais serviços relacionados à ordem da segurança pública. Em uma perspectiva comissiva, existe o dever de zelar pela prevenção contra incêndio e pânico e prezar pela prevenção de tragédias e acidentes urbanísticos e habitacionais. A competência do Corpo de Bombeiros é, assim, tanto preventiva quanto reativa.

No que tange à ordem urbanística, entrelaçam-se as searas militares e jurídicas, na medida em que o papel do CBM consolida requisitos fixos do paradigma da sustentabilidade e reforça a viabilidade dos princípios do Direito Ambiental, quais sejam, a precaução e a prevenção.

Ora, o Princípio da Precaução tem por fim a garantia de medidas suficientes para evitar as mazelas ambientais - sobretudo aquelas que representem risco considerável e irreversível que, por eventualidades, não possam ser previstas cientificamente. Assim, o Poder Público, por meio de seus instrumentos institucionais, deve promover orientações de cautela, cujo fim é impedir o desequilíbrio da multidimensionalidade sustentável. (THOMÉ, DIZ, 2018, p. 42)

Seguindo o que se dispõe, o Supremo Tribunal Federal referenda tal perspectiva ao estabelecer que a eficácia do Princípio da Precaução é direta e

8 A Lei deve orientar os atos da Administração Pública. 
faz imperar sobre o Estado Democrático de Direito diligências de caráter não tergiversáveis. Isto é, vige o dever da garantia do direito fundamental (de ordem humana) ao meio ambiente ecologicamente sadio - o que far-se-á pela adoção de medidas proporcionais nos casos em que pairam incertezas técnicocientíficas. (BRASIL, 2016)

Incumbe ao serviço de inteligência estratégica do Corpo de Bombeiros, portanto, a reflexão metodológica cujo fim é o delineado das potenciais problemáticas urbanas e habitacionais nas situações de incerteza. Mais que um comportamento tático, importa que a precaução coroe a instituição como política de ação - de forma que sua atuação seja satisfatória no que diz respeito à leitura de possíveis riscos e o impedimento antecipado de tragédias. (GONÇALVES, 2013, p. 128)

A precaução configura-se menos como protecionismo disfarçado e mais como um dever do Estado, em suas várias searas - dentre as quais o CBM é qualificado à percepção e leitura de colapsos potenciais e incertos. Assim, dizse que incumbe à instituição supramencionada descartar os riscos estruturais e relacionados a incêndio e pânico - principalmente - como desafio que remonta a própria gênese dos Bombeiros. (DALLARI, VENTURA, 2002, p. 57)

No que tange à prevenção, por sua vez, caberá à instituição agir antecipadamente - como forma de prevenir determinado fato degradante da ordem urbana e ambiental. (SIRVINSKAS, 2011, p. 106) Isto é, a missão constitucional se preocupou em considerar a maior facilidade em prevenir do que reparar danos - de forma que o Corpo de Bombeiros Militar pode [e deve] atuar tanto para evitar, quanto para combater eventos danosos. (CIELO et al, 2012, p. 99)

Assim, para além dos limites da precaução, o CBM é incumbido do dever de estabelecer condições para mitigação da possibilidade de riscos - o que se faz por meio de resoluções, portarias ou determinações técnicas frutos de estudos antecipados. Ora, tanto no combate e prevenção de incêndios, como na prevenção de colapsos estruturais urbanos e habitacionais, a 
instituição se depara com desafios que demandam rigoroso processo de análise e filtragem de percepções.

O que se diz, portanto, é que o Corpo de Bombeiros Militar, por meio de chefias e qualificação de seus membros através dos cursos de formação, adota papel importante na sociedade de risco. Isso porque são capazes de ultrapassar as percepções leigas acerca dos riscos reais, e também superar os paradigmas científicos que se prendem exclusivamente às matemáticas dos riscos. Assim, o CBM é capacitado para aliar a exatidão dos estudos dos riscos com as investigações sociais que demonstrem a variabilidade dos desastres. (FIGUEIREDO, 2018, p. 306)

A análise de risco realizada pelo CBM constitui amparo para a teoria das decisões que se pretende tomar - cujo fim é o resultado "de suas aplicações e do sucesso das decisões envolvidas". (FIGUEIREDO, 2018, p. 305) Assim, desde o estabelecimento de regras para brigadistas em eventos de médio a grande porte, até a lavratura de Alvarás de Prevenção de Incêndio e Pânico, a atuação do Corpo de Bombeiros Militar implica na satisfação preventiva e de precaução para granulação de riscos decorrentes das demandas e consequências tecnológicas da contemporaneidade.

\subsection{Prevenção de incêndio e pânico}

Considerando-se os aspectos de risco, a análise da prevenção de incêndios é de crucial importância para as questões habitacionais e urbanísticas. Ora, conforme supramencionado, a prevenção e a precaução como princípios basilares da sustentabilidade ${ }^{9}$ e dos legados constitucionais implicam na garantia da vida humana [digna] e do patrimônio, este último relativo (tanto no que diz respeito aos interesses particulares, quanto aos interesses difusos relacionados aos bens históricos e culturais, por exemplo),

9 Paradigma consolidada após a Convenção de Estocolmo, em 1972, com estipulação de um tripé para o Desenvolvimento da sociedade (social, ambiental, econômico). 
com três níveis de abordagem, quais sejam, político (órgãos legislativos), técnico científico (entidades de pesquisa e desenvolvimento tecnológico) e operacional (usuários e o Corpo de Bombeiros). (NETO, 1995, p. 11)

O papel dos envolvidos na seara operacional diz respeito, portanto, a participação nas atualizações de segurança dos processos marcados por complexidade estrutural das edificações, que envolvem a utilização de novos materiais e tecnologias. Assim, ao promover as devidas vistorias e análises acerca da segurança contra incêndios, o CBM evidencia o peso das perdas humanas e econômicas - superando as percepções de que projetos de segurança são simples atendimento burocrático a disposições legais. (NETO, 1995, p. 12)

Nesse sentido, importa ao CBM trabalhar em um tripé organizacional. Em primeiro lugar, a evacuação [talvez o mais complexo projeto] deve partir da premissa de garantir a sobreposição da importância da vida humana sobre os valores patrimoniais. Rotas para fuga devem ser pensadas com o fim de garantir a mobilidade de indivíduos em casos de incêndio e pânico - sobretudo em edifícios públicos, como hospitais.

Não obstante, tendo em vista a inviabilidade de um projeto de evacuação satisfatório para todos os ambientes vistoriados, há que se pensar em alternativa tática e estratégica, como a prevenção/proteção. Isso porque, é o próprio controle das possibilidades de início de incêndio que tornarão as demandas de evacuação mórbidas. "O empenho prevencionista e a proteção devem chegar ao nível de exigência em que as probabilidades de êxito sejam muito altas."(NETO, 1995, p. 14)

Por fim, mas não menos importante, impera promover a organização do espaço físico para garantia de diligências rápidas e satisfatórias em casos de necessidade - com restrições físicas "à propagação horizontal e vertical das chamas se, ainda assim, forem produzidas." (NETO, 1995, p. 14) Assim, evitase o pânico - responsável por desarmonizar as ordens sociais. 
A prevenção satisfatória de incêndios, nesse sentido, depende da articulação do Poder Público com suas especializadas, de forma que seja consolidada uma política robusta de proteção contra incêndios - que alie, principalmente, a Defesa Civil, os sistemas e tecnologias de combate do fogo e o planejamento de normas de prevenção que possibilitem o fortalecimento e livres diligências do Corpo de Bombeiros Militar.

A utilização de edificações modais pode ser importante para garantir a realização de pesquisas eficientes no planejamento estratégico para prevenção e combate de incêndios, sobretudo se considerar-se a escassez de dados estatísticos relacionados a incêndios no Brasil. Ademais, também importa a integração do CBM aos órgãos legislativos, com o fim de elaboração de normas consistentes que evitem a ocorrência de incêndios e pânico.

Ora, a importância da diligência supramencionada se confirma quando da verificação de que a maioria dos incêndios em residências ocorre nas edificações unifamiliares. Não surpreendentemente, estas são as únicas edificações em que se dispensa o sistema preventivo contra incêndio - na maioria dos estados da federação. Dessa forma, soa incontroversa a importância de um planejamento irrestrito e fortalecido pela integração das instituições. (CORRÊA, 2018, p. 125)

\subsection{Prevenção de desastres}

A prevenção de desastres diz respeito à construção de cidades resilientes, por efetivo planejamento e garantia das ordens estruturais. Ademais, demanda a construção de um olhar tático e estratégico capaz de promover perspectivas futuras das prioridades urbanas e habitacionais - com reflexos nas garantias humanas e econômicas.

Assim, incumbe ao Poder Público integrar a redução de riscos de desastres às políticas de sustentabilidade, bem como fortalecer as instituições ligadas à Defesa Civil para contribuírem com a criação de novos paradigmas 
comunitários, com a preparação de ações para casos de emergências [englobando planejamentos de resposta e condutas para recuperação]. (LEONI, 2012, p. 50)

O Corpo de Bombeiros Militar, como encarregado constitucional pela Defesa Civil, deve atuar - portanto - diligentemente para garantir a efetividade das referidas cidades resilientes, o que se dá por meio de ações em parcerias com órgãos essenciais à Justiça, como é o caso da atuação junto à Promotoria de Habitação e Urbanismo do Ministério Público.

Atendendo às demandas da ouvidoria do parquet, o Corpo de Bombeiros é oficiado para promover as atividades de vistoria e percepção das condições habitacionais e urbanísticas das edificações - com posterior lavratura de autos de notificação e envio de relatórios para a Promotoria [a qual incumbe a manutenção dos trâmites jurídicos para resolução dos entraves apontados pelo CBM]. O que se percebe é que a atividade integrada entre os órgãos públicos é eficiente para garantia da ordem social, vez que preservadas as competências e especialidades técnicas.

Ao contrário, quando são falhas as integrações organizacionais e ausentes os trabalhos de prevenção, o resultado esperado para qualquer ocorrência caótica tende a ser a morte de indivíduos. Ou seja, apesar de serem inevitáveis as perdas materiais nos referidos casos, as diligências de prevenção de desastres contribuem, significativamente, para a redução de perdas humanas - em conformidade com a tutela indispensável dos direitos de primeira dimensão. (BRASIL, 2007, p. 10)

Ademais, construir cidades resilientes implica também em garantir à população o entendimento dos riscos da sociedade, sob pena de fragilizar-se a eficácia de qualquer planejamento. "As análises e avaliações de risco são requisitos essenciais para o processo de decisão, priorização de projetos, planejamento para as medidas de redução de risco." (NAÇÕES UNIDAS, 2015, p. 34) 
Diz-se ser necessário ultrapassar as perspectivas micro para repensar uma resiliência macro, pautada no trabalho de coleta de informações sobre riscos e desastres, estudar programas de desenvolvimento territorial, avaliar riscos de acordo com as atividades, identificar pontos fortes e fracos nas tratativas das ameaças e, principalmente, sinalizar à sociedade as avaliações de risco. Este último ponto, note-se, levará ao último tópico do presente capítulo, que diz respeito à educação ambiental como instrumento de harmonização da ordem urbana e habitacional.

\subsection{Educação Ambiental}

Conforme lecionam Tettoet al (2011, p. 27), a origem de colapsos [sobretudo os incêndios] está relacionada ao analfabetismo ambiental. Isto é, os indivíduos da sociedade não projetam as consequências de seus atos, nem tem consciência acerca dos conceitos de sociedade de risco que pairam sobre a pós-modernidade.

Assim, importa ao Poder Público - em parceria com dados e análises realizadas pela especializada, qual seja o Corpo de Bombeiros Militar promover o processo de formação social orientado para "o desenvolvimento da consciência crítica sobre a questão ambiental.” (SOARES et al, 2009, p. 233)

Este, inclusive, trata-se de um importante legado da Política Nacional de Educação Ambiental, decorrente da Constituição Ecológica Brasileira. Ora, fica disposto no regramento supramencionado a indispensabilidade de garantir a construção de valores sociais, conhecimentos, habilidades, atitudes e competências voltadas para a conservação do meio ambiente [em seu sentido amplo], por meio de práticas educativas que garantam a sensibilização da coletividade. (BRASIL, 1999, art. 1º)

Acerca do referido processo de conscientização, é notado o trabalho do Corpo de Bombeiros Militar - sobretudo nas campanhas de combate a incêndios florestais, como o programa "Mata Viva", do CBMPR, e a operação 
"Corta Fogo", do CBMSP. Referidos trabalhos podem [e devem] ser espelhados para garantia da ordem habitacional e urbanística, minimizando e conscientizando acerca dos riscos que novos modelos estruturais e tecnológicos acarretam. Assim, pelas campanhas, "a educação ambiental pode agir estimulando nos indivíduos a percepção de que são parte integrante da natureza, e tem papel importante na proteção do meio ambiente" - e das cidades. (CAVALCA, CAVALCA, 2018, p. 91)

\section{CONSIDERAÇÕES FINAIS}

A constatação de uma sociedade de risco implica na percepção de incertezas constantes que circundam as atividades sociais. Dessa forma, diz-se que as relações homem-tecnologia-estruturas demanda uma postura reflexiva no que diz respeito ao fortalecimento de uma postura sistemática e preventiva.

Diz-se, portanto, acerca do papel do Corpo de Bombeiros Militar enquanto instrumento constitucional para promoção de estratégias e táticas pautadas nos princípios da prevenção e da precaução. Assim, mais que uma atividade combativa, impera ao CBM uma postura para evitar riscos - em uma conduta contra hegemônica, pautada na avaliação e constatação de riscos que demandem suporte técnico-científico.

Nesse tocante, a pesquisa apresentou um tripé deatuação da instituição, baseada em a) prevenção de incêndio e pânico; b) prevenção de desastres estruturais; c) educação ambiental. Assim, buscar-se-á a manutenção da ordem nas cidades por meio de vistorias preliminares que indiquem percentuais e probabilidades de risco e a adoção de medidas para prevenção.

Diz-se a respeito de um papel emancipador das cidades desempenhado pelo Corpo de Bombeiros Militar que, mais que garantir a ordem urbanística e habitacional, por meio de suas atividades de controle, consagra o bem-estar social - viabilizando os mandamentos da Carta Magna, que dizem respeito à dignidade humana e equilíbrio ambiental. 


\section{REFERÊNCIAS BIBLIOGRÁFICAS}

BRASIL. Ministério da Integração Nacional. Aspectos Jurídicos das atividades de Defesa Civil. 2007.

NETO, Manoel Altivo da Luz. Condições de segurança contra incêndio. Brasília: Ministério da Saúde. 1995.

MARTINS, Francisco das Chagas. A separação do Corpo de Bombeiros da Polícia Militar do Piauí como fator de Segurança Pública e Direitos Humanos. Teresina, 2001.

CBMGO. História da corporação. 2016. Disponível em: $<$ https://www.bombeiros.go.gov.br/wp-

content/uploads/2017/06/HIst\%C3\%B3rico.pdf>. Acesso em: 18 mar.2019.

THOMÉ, Romeu Faria. DIZ, Jamile Bergamaschine Mata. Princípio da precaução: definição de balizas para a prudente aplicação. Veredas do Direito: Belo Horizonte. v. 15, n. 32, p. 36-66, mai-ago. 2018.

BRASIL. Supremo Tribunal Federal. Recurso Extraordinário 627.189/SP. Relator: Dias Toffoli.Diário da Justiça, Brasília, 08 jun. 2016.

GONÇALVES, Vasco Barroso. O princípio da precaução e a gestão dos riscos ambientais: Contribuições e limitações dos modelos econômicos. Ambiente e Sociedade, São Paulo, v. 16, n. 4, p. 121-140, out-dez. 2013.

DALLARI, Sueli Gandolfi. VENTURA, Deisy de Freitas Lima. O princípio da precaução: dever do Estado ou protecionismo disfarçado? São Paulo em Perspectiva, São Paulo, v. 16, n. 2, p. 53-63. 2002.

SIRVINSKAS, Luís Paulo. Manual de direito ambiental. 9 ed. São Paulo: Saraiva, 2011.

CIELO, Patrícia Fortes Lopes Donzele. Uma leitura dos princípios da prevenção e da precaução e seus reflexos no Direito Ambiental. Revista CEPPG, v. 26, n. 01, p. 1996-207. 2002. 
CBMGO. Corpo de Bombeiros Militar do Estado de Goiás. Manual operacional dos bombeiros: Defesa Civil. Secretaria de Segurança Pública. 2018.

CORRÊA, Cristiano. Mapeamento dos incêndios em edificações: o edifício modal e suas aplicações. Revista FLAMMAE, Pernambuco. v. 04, n. 11, p. 113-153. 2018.

LEONI, Brigitte. $O$ desastre sob o enfoque de novas lentes: para cada efeito, uma causa. Trad. Sarah Marcela Chinchilla Cartagena. São Paulo: CARE Brasil, 2012.

NAÇÕES UNIDAS. Construindo cidades resilientes. Genebra: Escritório das Nações Unidas para Redução de Riscos de Desastres. 2015.

TETTO, A. et al. Zoneamento de risco de incêndios florestais para o estado do Paraná. Brasil In_SimpósioSul-americano sobre controle de incêndios florestais, v. 112, n. 12, 2011.

SOARES, Ronaldo Viana. et al. Incêndios florestais no Brasil: o estado da arte. Curitiba: UFPR, 2009.

BRASIL. Política Nacional de Educação Ambiental. Lei no 9.795/99.

CAVALCA, Alexandre Mançano. CAVALCA, Luisiana Guimarães. A educação Ambiental como ferramenta na prevenção de incêndios florestais. Revista FLAMMAE. v. 04, n. 11, p. 77-93. 2018.

BECK, Ulrich. Sociedade de Risco: Rumo a uma outra modernidade. Rio de Janeiro: Editora 34. 2011.

BECK, Ulrich. Incertezas fabricadas. IHU Online, São Leopoldo, maio, 2006.

KALOF, Linda. FITZGERALD, Amy. Reading thetrophy: exploringthe display ofdeadanimals in hunting magazines.Routledge. London. v. 18, n. 2, 2003.

FIGUEIREDO, Clayson Marlei. Os aspectos dos desastres sobre a ótica da sociedade de risco. Revista FLAMMAE, v. 04, n. 11, p. 301-315. 2018. 